\title{
Costimulatory B7-H1 in renal cell carcinoma patients: Indicator of tumor aggressiveness and potential therapeutic target
}

\author{
R. Houston Thompson*, Michael D. Gillett* ${ }^{\dagger}$, John C. Cheville ${ }^{\ddagger}$, Christine M. Lohse ${ }^{\S}$, Haidong Dong", W. Scott Webster*, \\ Kent G. Krejci*, John R. Lobo*, Shomik Sengupta*, Lieping Chenll, Horst Zincke*, Michael L. Blute*, Scott E. Strome**,

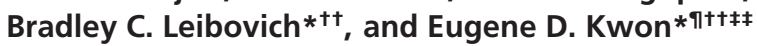

Departments of *Urology, „Laboratory Medicine and Pathology, §Health Sciences Research, ๆlmmunology, and **Otolaryngology, Mayo Medical School, Mayo Clinic, Rochester, MN 55905; and UDepartment of Dermatology and Oncology, Johns Hopkins University School of Medicine, Baltimore, MD 21287

Edited by James P. Allison, Memorial Sloan-Kettering Cancer Center, New York, NY, and approved October 25, 2004 (received for review August 27, 2004)

\begin{abstract}
Expression of B7-H1, a costimulating glycoprotein in the B7 family, is normally restricted to macrophage-lineage cells, providing a potential costimulatory signal source for regulation of $\mathrm{T}$ cell activation. In contrast, aberrant expression of B7-H1 by tumor cells has been implicated in impairment of $\mathrm{T}$ cell function and survival, resulting in defective host antitumoral immunity. The relationship between tumor-associated B7-H1 and clinical cancer progression is unknown. Herein, we report B7-H1 expression by both renal cell carcinoma (RCC) tumors of the kidney and RCC tumor-infiltrating lymphocytes. In addition, our analysis of 196 clinical specimens reveals that patients harboring high intratumoral expression levels of B7-H1, contributed by tumor cells alone, lymphocytes alone, or tumor and/or lymphocytes combined, exhibit aggressive tumors and are at markedly increased risk of death from RCC. In fact, patients with high tumor and/or lymphocyte B7-H1 levels are 4.5 times more likely to die from their cancer than patients exhibiting low levels of B7-H1 expression (risk ratio 4.53 ; $95 \%$ confidence interval 1.94-10.56; $P<0.001$.) Thus, our study suggests a previously undescribed mechanism whereby RCC may impair host immunity to foster tumor progression. B7-H1 may prove useful as a prognostic variable for RCC patients both pre- and posttreatment. In addition, B7-H1 may represent a promising target to facilitate more favorable responses in patients who require immunotherapy for treatment of advanced RCC.
\end{abstract}

costimulation | immunotherapy | T lymphocyte | tumor biomarker

nadequate, inappropriate, or inhibitory $\mathrm{T}$ cell costimulatory pathway signaling have all been shown to restrict a host's ability to generate productive immune responses against cancer. Related to this, the costimulatory ligand, B7-H1, has recently been implicated as a negative regulator of antitumoral $\mathrm{T}$ cell-mediated immunity. B7-H1 is a cell-surface glycoprotein belonging to the B7 family of costimulatory molecules (1). In humans, constitutive B7-H1 protein expression is normally limited to macrophage-lineage cells, although expression of B7-H1 can be induced on other hematologic cells as well, including activated $\mathrm{T}$ lymphocytes. In addition, aberrant tumor cell B7-H1 expression has been described in a number of human malignancies $(2,3)$. B7-H1 expressed by tumor cells has been shown to enhance apoptosis of activated tumor-specific T cells in vitro (2). Similarly, B7-H1 expressed on activated $\mathrm{T}$ cells has been demonstrated to impair both $\mathrm{T}$ cell function and survival (4). Consistent with these observations, in vivo monoclonal antibody blockade of B7-H1 has been shown to potentiate antitumoral responses in several murine cancer models (4-6). Thus, tumor-associated B7-H1 has recently garnered much attention as a potential inhibitor of host antitumoral immunity. However, evidence that tumor-associated $\mathrm{B} 7-\mathrm{H} 1$, or any other $\mathrm{T}$ cell costimulatory molecule, facilitates solid tumor progression in the clinical setting is lacking.
Approximately $30 \%$ of patients diagnosed with renal cell carcinoma (RCC) will present with widely disseminated disease (7). In addition, another $25-30 \%$ of patients treated for localized RCC will experience metastatic disease progression after surgical extirpation $(8,9)$. Median survival for patients with metastatic RCC is $\approx 6-10$ months with $<20 \%$ 2-year survival (10). Unfortunately, advanced RCC has proven to be refractory to traditional chemotherapy. In contrast, favorable treatment responses have been elicited in subsets of RCC patients receiving cytokine-based immunotherapy (11), T cell adoptive immunotherapy (12), or vaccination with a variety of autologous tumor cell preparations (13). It has also been shown that RCC tumors frequently harbor high levels of tumor-infiltrating lymphocytes $(14,15)$. Additionally, spontaneous complete regression of RCC metastases has been reported to occur, albeit on rare occasions, after radical nephrectomy (16). Thus, these observations implicate RCC as an immunogenic form of cancer that is amenable to immune-based therapy. However, relatively little is known about the potential mechanism whereby RCC might impair host immunity to facilitate subsequent tumor progression.

For this reason, we examined B7-H1 expression in human RCC. Herein, we report that RCC patients harboring high levels of either tumor-associated B7-H1 alone, infiltrating lymphocyteassociated B7-H1 alone, or tumor-associated and/or infiltrating lymphocyte-associated B7-H1 combined, exhibit aggressive tumors and are at markedly increased risk of death from RCC. Based on these observations, we surmise that B7-H1 expressed within RCC tumors may serve to facilitate tumor progression by undermining host antitumoral $\mathrm{T}$ cell-mediated immunity. As such, B7-H1 may represent a promising target for antitumoral immunotherapy and a valuable prognostic marker to predict outcome and treatment responses for patients afflicted with RCC.

\section{Materials and Methods}

Patient Selection. Upon approval from the Mayo Clinic Institutional Review Board, we identified 429 patients treated with radical nephrectomy or nephron-sparing surgery for unilateral sporadic clear cell RCC between 2000 and 2002 from the Mayo Clinic Nephrectomy Registry. Because pathologic features and patient outcome differ by RCC subtype, all analyses were restricted to patients treated with clear cell $\mathrm{RCC}$ only, the most

\footnotetext{
This paper was submitted directly (Track II) to the PNAS office.

Freely available online through the PNAS open access option.

Abbreviations: RCC, renal cell carcinoma; TNM, tumor node metastasis; $\mathrm{Cl}$, confidence interval.

${ }^{\dagger}$ R.H.T. and M.D.G. contributed equally to this work.

${ }^{+}$B.C.L. and E.D.K. contributed equally to this work.

¥¥To whom correspondence should be addressed. E-mail: kwon.eugene@mayo.edu.

C 2004 by The National Academy of Sciences of the USA
} 
common of the RCC subtypes (17). In addition, patients were selected based on availability of fresh-frozen tissue, because we have previously demonstrated that the human B7-H1-specific monoclonal antibody, $5 \mathrm{H} 1$, can reproducibly stain fresh-frozen but not paraffin-fixed tissue during immunohistochemical analysis (2).

Pathologic Features. The pathologic features examined included histologic subtype, tumor size, primary tumor stage, regional lymph node involvement and distant metastases at nephrectomy, nuclear grade, and histologic tumor necrosis. The microscopic slides from all specimens were reviewed by a urologic pathologist (J.C.C.) without prior knowledge of patient outcome. Histologic subtype was classified according to the Union Internationale Contre le Cancer, American Joint Committee on Cancer, and Heidelberg guidelines $(18,19)$. Nuclear grade was assigned by using standardized criteria as described (20). Histologic tumor necrosis was defined as the presence of any microscopic coagulative tumor necrosis. Degenerative changes such as hyalinization, hemorrhage, and fibrosis were not considered necrosis.

Immunohistochemical Staining of Tumor Specimens. Cryosections generated from RCC tumors and normal renal cortical specimens $\left(5 \mu \mathrm{m},-20^{\circ} \mathrm{C}\right)$ were mounted on Superfrost Plus slides, air dried, and fixed in ice-cold acetone. Sections were stained by using the Dako Autostainer and Dako Cytomation Labeled Polymer (EnVision + ) horseradish peroxidase detection kit (Dako, Carpinteria, CA). Slides were blocked with $\mathrm{H}_{2} \mathrm{O}_{2}$ for 10 min followed by incubation with the primary antibody applied for $30 \mathrm{~min}$ at room temperature. Labeled polymer was then applied at room temperature for $15 \mathrm{~min}$ followed by incubation with chromogen substrate for $10 \mathrm{~min}$. Finally, sections were counterstained for 3 min with modified Schmidt's hematoxylin. The primary antibody used in this study was $5 \mathrm{H} 1$, a mouse anti-human B7-H1 monoclonal antibody previously reported for human tumor staining by Dong et al. (2). Benign renal tumors and peripheral $\mathrm{T}$ cells were not stained in this study. Positive tissue controls for B7-H1 staining were human tonsillar tissues. Irrelevant isotype-matched antibodies were used to control for nonspecific staining.

Quantification of B7-H1 Expression. The percentages of tumor cells and lymphocytes that stained positive for B7-H1 were quantified in $5-10 \%$ increments by a urologic pathologist (J.C.C.) without prior knowledge of patient outcome. The extent of lymphocytic infiltration was assessed and recorded as absent, focal (scattered lymphoid aggregates), moderate, or marked. An adjusted score representing lymphocyte B7-H1 expression was calculated as the percentage of lymphocytes that stained positive for B7-H1 multiplied by the extent of lymphocytic infiltration $(0=$ absent, $1=$ focal, $2=$ moderate, and $3=$ marked).

Statistical Methods. Comparisons among the pathologic features and B7-H1 expression were evaluated by using $\chi^{2}$, Fisher's exact, and Wilcoxon rank sum tests. Cancer-specific survival was estimated by using the Kaplan-Meier method. The duration of follow-up was calculated from the date of nephrectomy to the date of death or last follow-up. Cause of death was determined from the death certificate or physician correspondence. Scatter plots of the percentage of cells that stained positive for B7-H1 versus the difference in observed survival and the survival expected from a Cox proportional hazards regression model (formally known as a Martingale residual) were used to identify potential cut points for B7-H1 expression (21). The associations of these cut points with death from RCC were evaluated by using Cox proportional hazards regression models univariately and after adjusting for primary tumor stage, regional lymph node
Table 1. Percent tumor B7-H1 expression in 196 clear cell RCC specimens

\% B7-H1 expression $n(\%)$

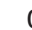

5 $66(33.7)$

$57(29.1)$

10

15

20

25

30

40

50

60

70

80

90

100

27 (13.8)

4 (2.0)

15 (7.7)

3 (1.5)

6 (3.1)

2 (1.0)

4 (2.0)

3 (1.5)

3 (1.5)

2 (1.0)

3 (1.5)

$1(0.5)$

involvement, distant metastases, tumor size, nuclear grade, and histologic tumor necrosis, one feature at a time. The association of B7-H1 expression with death from RCC was also adjusted for the Mayo Clinic Stage, Size, Grade, and Necrosis (SSIGN) Score, a prognostic composite score specifically developed for patients with clear cell RCC (22). Statistical analyses were performed by using the SAS software package (SAS Institute, Cary, NC), and $P$ values $<0.05$ were considered statistically significant.

\section{Results}

Comparison of Patients With and Without Fresh-Frozen Tissue. Of the 429 patients eligible for study, 196 (46\%) had fresh-frozen tissue available for laboratory investigation. Patients with fresh-frozen tissues had larger tumors compared with those who did not (median tumor size $6.0 \mathrm{~cm}$ versus $5.0 \mathrm{~cm} ; P=$ $0.008)$. However, no other feature studied was significantly different between the two groups. Furthermore, there was not a statistically significant difference in cancer-specific survival between patients with and without fresh-frozen tissues $(P=$ $0.314)$.

Follow-Up for the 196 Patients Studied. At last follow-up, 39 of the 196 patients studied had died, including 30 patients who died from clear cell RCC at a median of 1.1 years after nephrectomy (range 0-2.5). Among the 157 patients who were still alive at last follow-up, the median duration of follow-up was 2.0 years (range $0-4.1$ ). The estimated cancer-specific survival rates (standard error, number still at risk) at 1,2, and 3 years after nephrectomy were $91.4 \%(2.1 \%, 148), 81.8 \%(3.3 \%, 78)$, and $77.9 \%(3.8 \%$, $30)$, respectively.

B7-H1 Expression. Immunohistochemical staining of the 196 clear cell RCC specimens revealed either no B7-H1 expression by $\mathrm{RCC}$ tumor cells or varying degrees of B7-H1 expressed by either RCC tumor cells and/or RCC tumor-infiltrating lymphocytes (Tables 1 and 2 and Fig. 1). In addition, proximal tubules within the renal cortex, from which RCC tumors are believed to arise, exhibited no B7-H1 expression among the 20 normal renal cortical specimens studied (Fig. 1).

The percentages of tumor cells that stained positive for B7-H1 for the 196 specimens studied are summarized in Table 1. A scatter plot of tumor B7-H1 expression versus the expected risk of death for each patient suggested that a cut point of $10 \%$ would be appropriate for these data. There were $73(37.2 \%)$ patients with specimens that had $\geq 10 \%$ tumor B7-H1 expression. The associations of tumor B7-H1 expres- 


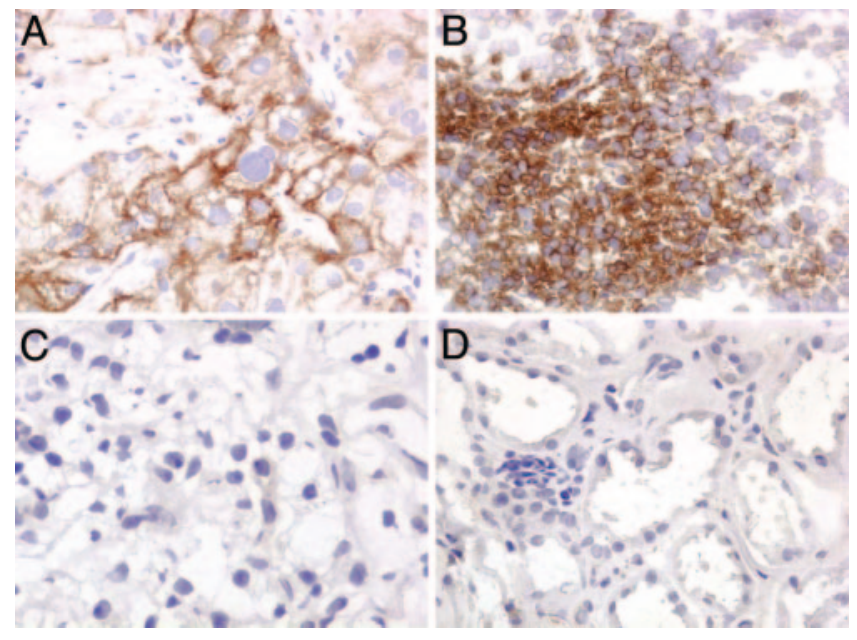

Fig. 1. Photomicrographs at $\times 400$. (A) RCC specimen with high tumor $B 7-H 1$ expression. (B) RCC specimen with high lymphocyte B7-H1 expression. (C) RCC specimen with no B7-H1 staining in either the tumor cells or lymphocytes. $(D)$ Normal kidney specimen with no B7-H1 staining in the proximal tubules.

sion with death from RCC, both univariately and after adjusting for tumor node metastasis (TNM) stage, tumor size, nuclear grade, and histologic tumor necrosis, are shown in Table 3. Univariately, patients with specimens that had $\geq 10 \%$ tumor B7-H1 expression were close to 3 times more likely to die from RCC compared with patients with specimens that had
$<10 \%$ expression [risk ratio $2.91 ; 95 \%$ confidence interval (CI) $1.39-6.13 ; P=0.005$; Fig. $2 A$ ]. In multivariate analyses, patients with specimens that had $\geq 10 \%$ tumor B7-H1 expression were significantly more likely to die from RCC even after adjusting for primary tumor stage, distant metastases, or primary tumor size.

The adjusted scores for lymphocyte B7-H1 expression are summarized in Table 2. There were $40(20.4 \%)$ specimens with an adjusted lymphocyte B7-H1 score of 100 or greater (essentially moderate or marked lymphocytic infiltration with at least $50 \%$ of the lymphocytes staining positive for B7-H1), which appeared to be a reasonable cut point to examine and illustrate the association of this feature with patient outcome. The associations of lymphocyte B7-H1 expression with death from RCC are summarized in Table 3. Univariately, patients with specimens that had an adjusted lymphocyte B7-H1 score $\geq 100$ were 3.6 times more likely to die from RCC compared with patients that had specimens with scores $<100$ (risk ratio 3.58; $95 \% \mathrm{CI}$ 1.74-7.37; $P<0.001$; Fig. $2 B$ ). Patients with specimens that demonstrated high levels of lymphocyte B7-H1 expression were significantly more likely to die from RCC even after adjusting for TNM stage, primary tumor size, nuclear grade, or histologic tumor necrosis.

Because both tumor and lymphocyte B7-H1 expression were significantly associated with patient outcome both univariately and after multivariate adjustment, we evaluated the combination of these two features. There were 87 (44.4\%) specimens that had either $\geq 10 \%$ tumor B7-H1 expression or an adjusted score for lymphocyte B7-H1 expression $\geq 100$ (i.e., highaggregate intratumoral B7-H1 expression). Twenty-six

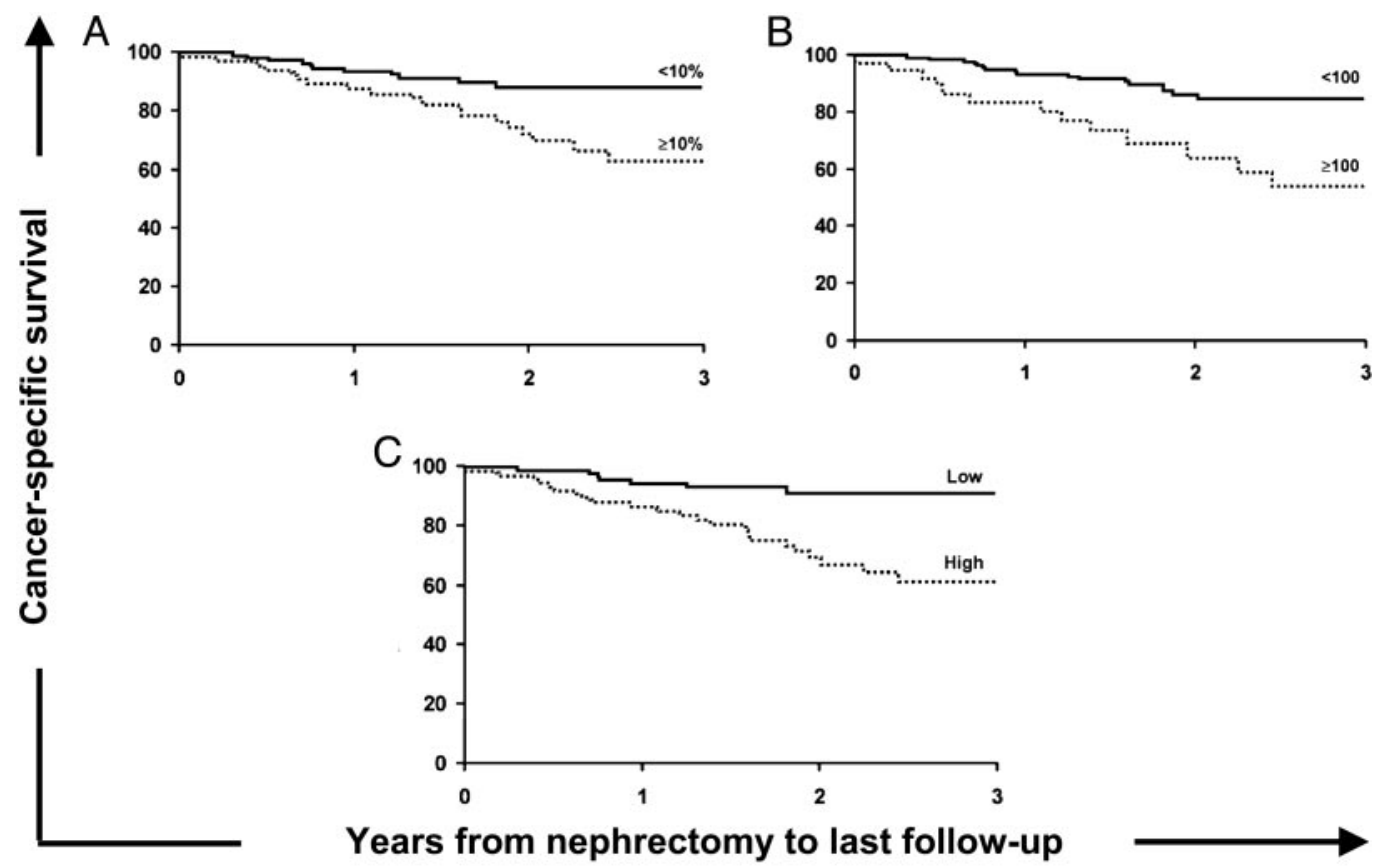

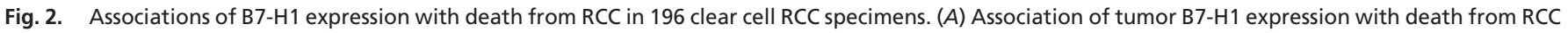

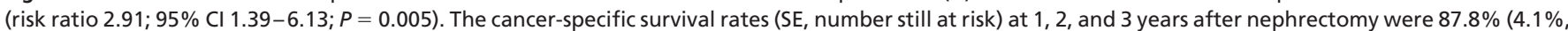

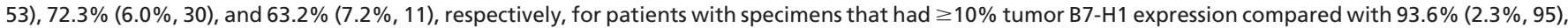

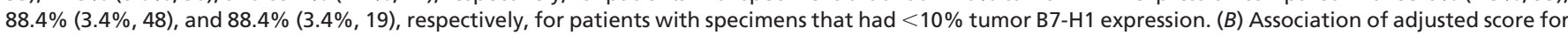

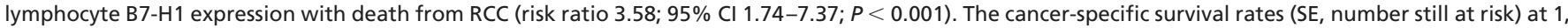

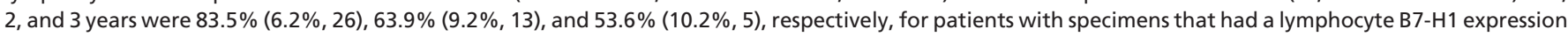

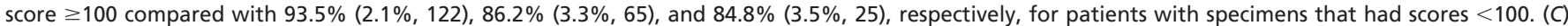

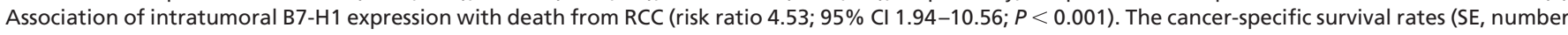

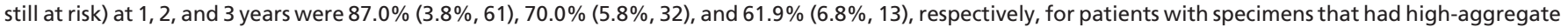

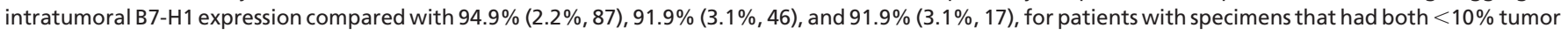
and $<100$ lymphocyte (low) B7-H1 expression. 
Table 2. Adjusted score for lymphocyte B7-H1 expression in 196 clear cell RCC specimens

\begin{tabular}{lccc}
$\begin{array}{l}\text { Lymphocytic } \\
\text { infiltration* }\end{array}$ & $\begin{array}{c}\text { \% B7-H1 } \\
\text { expression }\end{array}$ & $\begin{array}{c}\text { Adjusted } \\
\text { score }\end{array}$ & $n(\%)$ \\
\hline 0 & 0 & 0 & $81(41.3)$ \\
1 & 5 & 5 & $4(2.0)$ \\
1 & 10 & 10 & $1(0.5)$ \\
1 & 30 & 30 & $2(1.0)$ \\
1 & 50 & 50 & $4(2.0)$ \\
1 & 60 & 60 & $3(1.5)$ \\
1 & 70 & 70 & $22(11.2)$ \\
1 & 80 & 80 & $12(6.1)$ \\
1 & 90 & 90 & $10(5.1)$ \\
2 & 5 & 10 & $3(1.5)$ \\
2 & 10 & 20 & $4(2.0)$ \\
2 & 20 & 40 & $2(1.0)$ \\
2 & 30 & 60 & $2(1.0)$ \\
2 & 50 & 100 & $6(3.1)$ \\
2 & 60 & 120 & $1(0.5)$ \\
2 & 70 & 140 & $9(4.6)$ \\
2 & 80 & 160 & $7(3.6)$ \\
2 & 90 & 180 & $8(4.1)$ \\
3 & 5 & 15 & $1(0.5)$ \\
3 & 20 & 60 & $1(0.5)$ \\
3 & 30 & 90 & $4(2.0)$ \\
3 & 70 & 210 & $2(1.0)$ \\
3 & 80 & 240 & $4(2.0)$ \\
3 & 90 & 270 & $2(1.0)$ \\
3 & 100 & 300 & $1(0.5)$ \\
\hline
\end{tabular}

*The extent of lymphocytic infiltration was recorded as $0=$ absent, $1=$ focally present, 2 = moderately present, or 3 = markedly present.

$(13.3 \%)$ of these specimens had both features. Conversely, 109 $(55.6 \%)$ specimens had $<10 \%$ tumor B7-H1 expression and $<100$ lymphocyte B7-H1 expression. The associations of this combined feature with death from RCC are summarized in Table 3. Univariately, patients with specimens that had high intratumoral B7-H1 expression were 4.5 times more likely to die from RCC compared with patients with specimens that had both $<10 \%$ tumor expression and $<100$ lymphocyte expression (risk ratio 4.53; 95\% CI 1.94-10.56; $P<0.001$ ). After adjusting for the Mayo Clinic Stage, Size, Grade, and Necrosis (SSIGN) Score, patients with high intratumoral B7-H1 expression remained over twice as likely to die from RCC compared with patients with low intratumoral B7-H1, although this difference did not attain statistical significance (risk ratio $2.19 ; 95 \%$ CI $0.91-5.24 ; P=0.079$ ). However, patients with specimens that had high intratumoral B7-H1 expression were significantly more likely to die from RCC after adjusting for TNM stage, primary tumor size, nuclear grade, and histologic tumor necrosis, one feature at a time. We also investigated the association of combined tumor and lymphocyte B7-H1 expression with the pathologic features under study and found that high-aggregate intratumoral B7-H1 expression levels were significantly associated with regional lymph node involvement, distant metastases, advanced nuclear grade, and the presence of histologic tumor necrosis (Table 4).

\section{Discussion}

To our knowledge, expression of B7-H1 within RCC tumors of the kidney has not been previously demonstrated. We also believe that B7-H1 is the first T cell costimulatory molecule that has been reported to exhibit a strong association with the aggressiveness of a solid (nonhematologic) tumor and patient cancer-specific survival. Finally, our study provides previously
Table 3. Associations of B7-H1 expression with death from RCC in 196 clear cell RCC specimens

\begin{tabular}{|c|c|c|}
\hline & $\begin{array}{l}\text { Risk ratio } \\
(95 \% \mathrm{Cl})^{*}\end{array}$ & $P$ value \\
\hline \multicolumn{3}{|l|}{ Tumor B7-H1 expression $\geq 10 \%$} \\
\hline Univariate model & $2.91(1.39-6.13)$ & 0.005 \\
\hline \multicolumn{3}{|l|}{ Adjusted for: } \\
\hline 2002 primary tumor stage $(T)$ & $2.83(1.34-5.96)$ & 0.006 \\
\hline Regional lymph node involvement (N) & $1.97(0.87-4.45)$ & 0.103 \\
\hline Distant metastases (M) & $2.24(1.06-4.73)$ & 0.035 \\
\hline Primary tumor size & $2.88(1.37-6.06)$ & 0.005 \\
\hline Nuclear grade & $1.96(0.90-4.30)$ & 0.092 \\
\hline Histologic tumor necrosis & $1.69(0.78-3.65)$ & 0.183 \\
\hline \multicolumn{3}{|l|}{ Lymphocyte $\mathrm{B} 7-\mathrm{H} 1$ expression $\geq 100$} \\
\hline Univariate model & $3.58(1.74-7.37)$ & $<0.001$ \\
\hline \multicolumn{3}{|l|}{ Adjusted for: } \\
\hline 2002 primary tumor stage $(T)$ & $3.34(1.62-6.90)$ & 0.001 \\
\hline Regional lymph node involvement $(\mathrm{N})$ & $3.59(1.74-7.41)$ & $<0.001$ \\
\hline Distant metastases $(\mathrm{M})$ & $2.16(1.03-4.53)$ & 0.042 \\
\hline Primary tumor size & $2.64(1.27-5.46)$ & 0.009 \\
\hline Nuclear grade & $3.03(1.46-6.29)$ & 0.003 \\
\hline Histologic tumor necrosis & $2.87(1.39-5.95)$ & 0.004 \\
\hline \multicolumn{3}{|l|}{ High-aggregate intratumoral $\mathrm{B} 7-\mathrm{H} 1$ expression } \\
\hline Univariate model & $4.53(1.94-10.56)$ & $<0.001$ \\
\hline \multicolumn{3}{|l|}{ Adjusted for: } \\
\hline 2002 primary tumor stage $(T)$ & $4.07(1.74-9.51)$ & 0.001 \\
\hline Regional lymph node involvement (N) & $3.36(1.39-8.16)$ & 0.007 \\
\hline Distant metastases (M) & $3.12(1.32-7.38)$ & 0.009 \\
\hline Primary tumor size & $4.25(1.82-9.91)$ & $<0.001$ \\
\hline Nuclear grade & $3.09(1.28-7.50)$ & 0.012 \\
\hline Histologic-tumor necrosis & $2.68(1.12-6.42)$ & 0.027 \\
\hline
\end{tabular}

*Risk ratios represent the risk of death from clear cell RCC for the feature listed, either univariately or after multivariate adjustment. For example, patients with specimens that had $\geq 10 \%$ tumor $\mathrm{B} 7-\mathrm{H} 1$ expression were 2.9 times more likely to die from RCC compared with patients with specimens that had $<10 \%$ tumor $\mathrm{B} 7-\mathrm{H} 1$ expression, even after adjusting for primary tumor size $(P=0.005)$.

undescribed evidence that B7-H1 may function at the clinical level to promote cancer progression, perhaps through impairment of host $\mathrm{T}$ cell-mediated immunity, as has recently been reported in the basic scientific literature $(2,6)$.

B7-H1 represents a recently identified cell-surface glycoprotein belonging to the $\mathrm{B} 7$ family of costimulatory molecules (1). Constitutive B7-H1 protein expression is normally restricted to macrophage-lineage cells, where it may participate in the costimulatory activation of naïve $\mathrm{T}$ cells or deletion of activated $T$ cells $(1,23)$. Several human cancers, however, have also been reported to aberrantly express B7-H1, including glioblastoma, melanoma, and cancers arising from the lung, ovary, colon, head and neck, and breast $(2,3,24)$. Tumorassociated B7-H1 has been shown to inhibit antitumoral $\mathrm{T}$ cell immunity by interacting with $\mathrm{T}$ cell $\mathrm{PD}-1$ or a putative non-PD-1 receptor to induce tumor-specific $T$ cell apoptosis or by impairing cytokine production and the cytotoxicity of activated T cells $(2,6,24,25)$. Similarly, it has been shown that activated T cells also express B7-H1, and that reverse signaling through T cell-associated B7-H1 can down-regulate primed T cell responses through the induction of apoptosis and/or inhibition of $\mathrm{T}$ cell clonal expansion (26). Conversely, antibody-mediated blockade of tumor-associated B7-H1 has been shown to potentiate antitumoral $\mathrm{T}$ cell responses directed against artificially transfected $\mathrm{B} 7-\mathrm{H} 1$ positive tumors in mice $(2,5,6)$. Thus, B7-H1 may function in the periphery as a negative regulator of effector $\mathrm{T}$ cell-mediated antitumoral 
Table 4. Associations of tumor and lymphocyte B7-H1 expression with pathologic features in 196 clear cell RCC specimens

\begin{tabular}{lccc} 
& \multicolumn{2}{c}{$\begin{array}{c}\text { High-aggregate } \\
\text { intratumoral B7-H1 }\end{array}$} & \\
& \multicolumn{2}{c}{$\begin{array}{c}\text { No } \\
\text { expression, } n(\%)\end{array}$} & \\
\cline { 2 - 3 } & $n=109$ & $n=87$ & P value \\
Feature & & & \\
\hline 2002 primary tumor stage & $88(80.7)$ & $62(71.3)$ & 0.120 \\
pT1 and pT2 & $21(19.3)$ & $25(28.7)$ & \\
pT3 and pT4 & & & \\
Regional lymph node involvement & $108(99.1)$ & $76(87.4)$ & $<0.001$ \\
pNx and pN0 & $1(0.9)$ & $11(12.6)$ & \\
pN1 and pN2 & & & \\
Distant metastases & $99(90.8)$ & $69(79.3)$ & 0.022 \\
pM0 & $10(9.2)$ & $18(20.7)$ & \\
pM1 & & & \\
Primary tumor size & $46(42.2)$ & $25(28.7)$ & 0.051 \\
$\quad<5$ cm & $63(57.8)$ & $62(71.3)$ & \\
$\geq 5$ cm & & & \\
Nuclear grade & $69(63.3)$ & $23(26.4)$ & $<0.001$ \\
1 and 2 & $36(33.0)$ & $50(57.5)$ & \\
3 & $4(3.7)$ & $14(16.1)$ & \\
4 & & & \\
Histologic tumor necrosis & $94(86.2)$ & $55(63.2)$ & $<0.001$ \\
Absent & $15(13.8)$ & $32(36.8)$ & \\
Present & & & \\
\hline
\end{tabular}

immunity, thereby fostering unfettered tumor progression in a setting of impaired host immune surveillance.

Consistent with these observations, we demonstrate that clear cell cancers of the kidney, which account for $\approx 70 \%$ of all renal malignancies (27), are capable of expressing B7-H1. In contrast, proximal tubules of the renal cortex, from which clear cell tumors are believed to arise, fail to express B7-H1 (2). In addition, our analyses reveal that elevated tumor cell B7-H1 expression levels are associated with a nearly 3-fold increased risk for RCC-specific death, and that enhanced levels of tumor-infiltrating lymphocyte-associated B7-H1 also increase the risk of RCC-specific death (risk ratio of 3.58). Moreover, the combination of increased tumor cell B7-H1 and/or lymphocyte B7-H1 (high-aggregate intratumoral B7-H1) is an even stronger predictor of patient outcome (risk ratio of 4.53). This combined feature is also significantly associated with regional lymph node involvement, distant metastases, nuclear grade, and histologic tumor necrosis, all of which have been shown to portend a poor prognosis (Table 4). Yet, even after adjusting for each of these features, the significant association of aggregate intratumoral B7-H1 with RCC-specific death persists (Table 3).

Our observation that intratumoral B7-H1 might facilitate RCC progression and diminish patient survival may have important implications for the immunobiology and immunotherapeutic treatment of RCC tumors. For instance, several studies have reported defective antitumoral immunity in RCC patients. Such defects in immunity have been partly ascribed to up-regulated intratumoral expression of immunosuppressive TGF- $\beta$, IL-10, and FasL, as well as impairment of tumor-infiltrating lymphocyte proliferation, intracellular signaling, effector function, and survival (28-34). In addition, two recent studies have reported a seemingly paradoxical relationship between increased levels of tumor-infiltrating $\mathrm{T}$ cells and poorer prognosis for RCC patients $(14,15)$. Thus, based on its recognized ability to impair the function and survival of activated tumor-specific $\mathrm{T}$ cells, we infer that B7-H1, expressed by either RCC tumor cells or infiltrating lymphocytes, may contribute to the profile of immunosuppression that is observed in patients with RCC. We further speculate that intratumoral B7-H1 functions as a critical host determinant of treatment responses in patients who receive immunotherapy for management of advanced RCC (i.e., IL-2, IFN- $\alpha$, vaccination, or $\mathrm{T}$ cell adoptive therapy). At present, systemic IL-2 immunotherapy represents the most effective and only Food and Drug Administration-approved treatment for metastatic RCC. Unfortunately, high-dose IL-2 therapy is associated with significant toxicity and provides a noncurative benefit to only $15-20 \%$ of RCC patients treated $(35,36)$. Thus, there exists a pressing demand for effective adjunctive manipulations to improve current forms of immunotherapy as well as newer methods to identify the subset of RCC patients that will derive the greatest benefit from immunotherapeutic intervention.

A compelling precedent for abrogating inhibitory $\mathrm{T}$ cell signaling to potentiate cell-mediated antitumoral immunity has been established by the experience with in vivo CTLA-4 blockade immunotherapy (37-39). Perhaps analogous to this, antibody-mediated in vivo blockade of tumor B7-H1 to preempt tumor B7-H1-induced impairment of host immunity has been shown to facilitate antitumoral responses in several murine cancer models (4-6). Thus, antibody-mediated blockade of B7-H1 may ultimately prove useful, either alone or in combination with other immune-based manipulations, to improve the effectiveness of RCC treatment. In addition, B7-H1 may serve as a biomarker to identify subsets of RCC patients most likely to derive benefit from immunotherapeutic treatment. As is the case with a number of other RCC markers that have recently been described (40-45), B7-H1 expression may also be useful when used in combination with more traditional pathologic indices such as TNM stage, tumor grade, and necrosis to ascertain the prognosis of patients afflicted with RCC.

However, we do acknowledge one limitation of the current study that relates to the relatively short duration of patient follow-up. Specifically, the anti-B7-H1 antibody that we used to stain RCC tumors is reliable only for immunohistochemical analysis of fresh-frozen tissues (2), and collection of freshfrozen RCC specimens at our institution was only recently initiated (January 2000). Nevertheless, despite observing only 30 deaths from RCC resulting in limited statistical power, patients with high-aggregate B7-H1 expression remained over twice as likely to die from RCC even after controlling for the Mayo Clinic Stage, Size, Grade, and Necrosis (SSIGN) Score (risk ratio $2.19 ; 95 \%$ CI $0.91-5.24 ; P=0.079$ ). Although this did not attain our specified 0.05 level of significance, we believe that this association will achieve significance with additional samples and continued follow-up. Furthermore, although it is tempting to attribute the immune dysfunction in $\mathrm{RCC}$ to aberrant B7-H1 expression, it is likely that multiple other host factors also contribute. Other immunosuppressive costimulatory molecules, including CTLA-4 and regulatory T cells such as CD4 + CD25 $+\mathrm{T}$ cells, remain understudied in RCC and may similarly facilitate the down-regulation of antitumoral $\mathrm{T}$ cell responses.

\section{Conclusion}

We report that elevated $\mathrm{B} 7-\mathrm{H} 1$ expression in $\mathrm{RCC}$ tumors of the kidney is significantly associated with aggressive tumors and enhanced risk for RCC-specific death. The basis for this association may relate to the recognized ability of tumor B7-H1 to inhibit T cell-mediated immunity. As such, B7-H1 may represent a target for RCC immunotherapy and a potential biomarker to facilitate patient assignment to treatment, as well as aid in the determination of prognosis both before and after therapy. 
1. Dong, H., Zhu, G., Tamada, K. \& Chen L. (1999) Nat. Med. 5, 1365-1369.

2. Dong, H., Strome, S.-E., Salomao, D.-R., Tamura, H., Hirano, F., Flies, D.-B., Roche, P.-C., Lu, J., Zhu, G., Tamada, K., et al. (2002) Nat. Med. 8, 793-800.

3. Strome, S.-E. \& Chen, L. (2004) Curr. Treat. Options Oncol. 5, 27-33.

4. Dong, H. \& Chen, L. (2003) J. Mol. Med. 81, 281-287.

5. Strome, S.-E., Dong, H., Tamura, H., Voss, S.-G., Flies, D.-B., Tamada, K., Salomao, D., Cheville, J.-C, Hirano, F., Lin, W., et al. (2003) Cancer Res. 63, 6501-6505.

6. Iwai, Y., Ishida, M., Tanaka, Y., Okazaki, T., Honjo, T. \& Minato, N. (2002) Proc. Natl. Acad. Sci. USA 99, 12293-12297.

7. Curti, B.-D. (2004) J. Am. Med. Assoc. 292, 97-100.

8. Levy, D.-A., Slaton, J.-W., Swanson, D.-A. \& Dinney, C.-P. (1998) J. Urol. 159, 1163-1167.

9. Ljungberg, B., Alamdari, F.-I., Rasmuson, T. \& Roos, G. (1999) Br. J. Urol. Int. 84, 405-411.

10. Figlin, R.-A., Pierce, W.-C., Kaboo, R., Tso, C.-L., Moldawer, N., Gitlitz, B., deKernion, J. \& Belldegrun, A. (1997) J. Urol. 158, 740-745.

11. Yang, J.-C., Sherry, R.-M., Steinberg, S.-M., Topalian, S.-L., Schwartzentruber, A.-J., Hwu, P., Seipp, C.-A., Rogers-Freezer, L. Morton, K.-E., White, D.-E., et al. (2003) J. Clin. Oncol. 21, 3127-3132.

12. Graham, S., Babayan, R.-K., Lamm, D.-L., Sawczuk, I., Ross, S.-D., Lavin, P.-T., Osband, M.-E. \& Krane, R.-J. (1993) Semin. Urol. 11, 27-34.

13. Krejci, K.-G., Markiewicz, M.-A. \& Kwon, E.-D. (2003) J. Urol. 171, 870-876.

14. Bromwich, E.-J., McArdle, P.-A., Canna, K., McMillan, D.-C., McNicol, A.-M., Brown, M. \& Aitchison, M. (2003) Br. J. Cancer 89, 1906-1908.

15. Nakano, O., Sato, M., Naito, Y., Suzuki, K., Orikasa, S., Aizawa, M., Suzuki, Y., Shintaku, I., Nagura, H. \& Ohtani, H. (2001) Cancer Res. 61, 5132-5136.

16. Couillard, D.-R. \& DeVere-White, R.-W. (1993) Urol. Clin. N. Am. 20, 263-275.

17. Cheville, J.-C., Lohse, C.-M., Zincke, H., Weaver, A.-L. \& Blute, M.-L. (2003) Am. J. Surg. Pathol. 27, 612-624.

18. Storkel, S., Eble, J.-N., Adlakha, K., Amin, M., Blute, M.-L., Bostwick, D.-G., Darson, M., Delahunt, B. \& Iczkowski, K. (1997) Cancer 80, 987-989.

19. Kovacs, G., Akhtar, M., Beckwith, B.-J., Bugert, P., Cooper, C.-S., Delahunt, B., Eble, J.-N., Fleming, S., Ljungberg, B., Medeiros, L.-J., et al. (1997) J. Pathol. 183, 131-133.

20. Lohse, C.-M., Blute, M.-L., Zincke, H., Weaver, A.-L. \& Cheville, J.-C. (2002) Am. J. Clin. Pathol. 118, 877-886.

21. Therneau, T.-M. \& Grambsch, P.-M. (2000) in Modeling Survival Data: Extending the Cox Model (Springer, Ann Arbor, MI), 1st Ed., pp. 87-92.

22. Frank, I., Blute, M.-L., Cheville, J.-C., Lohse, C.-M., Weaver, A.-L. \& Zincke, H. (2002) J. Urol. 168, 2395-2400.

23. Dong, H., Zhu, G., Tamada, K., Flies, D.-B., van Deursen, J.-M. \& Chen, L. (2004) Immunity 20, 327-336.

24. Wintterle, S., Schreiner, B., Mitsdoerffer, M., Schneider, D., Chen, L., Meyermann, R., Weller, M. \& Wiendl, H. (2003) Cancer Res. 63, 7462-7467.

25. Blank, C., Brown, I., Peterson, A.-C., Spiotto, M., Iwai, Y., Honjo, T. \& Gajewski, T.-F. (2004) Cancer Res. 64, 1140-1145.
26. Dong, H., Strome, S.-E., Matteson, E.-L., Moder, K.-G., Flies, D.-B., Zhu, G., Tamura, H., Driscoll, C.-L. \& Chen, L. (2003) J. Clin. Invest. 111, 363-370.

27. Pantuck, A.-J., Zisman, A. \& Belldegrun, A.-S. (2001) J. Urol. 166, 1611-1623.

28. Uzzo, R.-G., Rayman, P., Kolenko, V., Clark, P.-E., Bloom, T., Ward, A.-M. Molto, L., Tannenbaum, C., Worford, L.-J, Bukowski, R.-M., et al. (1999) Clin. Cancer Res. 5, 1219-1229.

29. Nakagomi, H., Pisa, P., Pisa, E.-K., Yamamoto, Y., Halapi, E., Backlin, K., Juhlin, C. \& Kiessling, R. (1995) Int. J. Cancer 63, 366-371.

30. Copland, J.-A., Luxon, B.-A., Ajani, L., Maity, T., Campagnaro, E., Guo, H., LeGrand, S.-N., Tamboli, P. \& Wood, C.-G. (2003) Oncogene 22, 8053-8062.

31. Lahn, M., Fisch, P., Kohler, G., Kunzmann, R., Hentrich, I., Jesuiter, H., Behringer, D., Muschal, B., Veelken, H., Kulmburg, P., et al. (1999) Eur. Urol. 35, 70-80.

32. Alexander, J.-P., Kudoh, S., Melsop, K.-A., Hamilton, T.-A., Edinger, M.-G., Tubbs, R.-R., Sica, D., Tuason, L., Klein, E., Bukowski, R., et al. (1993) Cancer. Res. 53, 1380-1387.

33. Li, X., Liu, J., Park, J.-K., Hamilton, T.-A., Rayman, P., Klein, E., Edinger, M., Tubbs, R., Bukowski, R. \& Finke, J. (1994) Cancer Res. 54, 5424-5429.

34. Kudoh, S., Redovan, C., Rayman, P., Edinger, M., Tubbs, R.-R., Novick, A., Finke, J.-H. \& Bukowski, R.-M. (1997) J. Immunol. 20, 479-487.

35. Rini, B.-I., Wwinberg, V. \& Small, E.-J., (2004) J. Urol. 171, 2115-2121.

36. Motzer, R.-J. (2003) Crit. Rev. Oncol. Hematol. 46S, s33-s39.

37. Hodi, F.-S., Mihm, M.-C., Soiffer, R.-J., Haluska, F.-G., Butler, M., Seiden, M.-V., Davis, T., Henry-Spires, R., MacRae, S., Willman, A., et al. (2003) Proc. Natl. Acad. Sci. USA 100, 4712-4717.

38. Phan, G.-Q., Yang, J.-C., Sherry, R.-M., Hwu, P., Topalian, S.-L., Schwartzentruber, D.-J., Restifo, N.-P., Haworth, L.-R., Seipp, C.-A., Freezer, L.-J., et al. (2003) Proc. Natl. Acad. Sci. USA 100, 8372-8377.

39. Egen, J.-G., Kuhns, M.-S. \& Allison, J.-P. (2002) Nat. Immunol. 3, 611-618.

40. Hofmockel, G., Tsatalpas, P., Muller, H., Dammrich, J., Poot, M., MaurerSchultze, B., Muller-Hermelink, H.-K., Frohmuller, H.-G. \& Bassukas, I.-D. (1995) Cancer 76, 296-306.

41. Tannapfel, A., Hahn, H.-A., Katalinic, A., Fietkau, R.-J., Kuhn, R. \& Wittekind, C.-W. (1996) Cancer 77, 164-171.

42. Delahunt, B., Bethwaite, P.-B., Nacey, J.-N. \& Ribas, J.-L. (1993) J. Pathol. 170, 471-477.

43. Bui, M.-H., Visapaa, H., Seligson, D., Kim, H., Han, K.-R., Huang, Y. Horvath, S., Stanbridge, E.-J., Palotie, A., Figlin, R.-A., et al. (2004) J. Urol. 171, 2461-2466.

44. Shimazui, T., Oosterwijk, E., Akaza, H., Bringuier, P., Ruijter, E., van Berkel, H., Wakka, J.-O., van Bokhoven, A., Debruyne, F.-M. \& Schalken, J.-A. (1998) Clin. Cancer Res. 4, 2419-2424.

45. Uhlman, D.-L., Nguyen, P.-L., Manivel, J.-C., Aeppli, D., Resnick, J.-M., Fraley, E.-E., Zhang, G. \& Niehans, G.-A. (1994) J. Natl. Cancer Inst. 86, 1470-1474. 